\title{
Stress Relieve in High Rigidity Metal Component Added Mass by Vibration
}

\author{
Xue-Wu DONG ${ }^{1, a^{*}}$, Bing $\mathrm{LI}^{1, \mathrm{~b}}$, Jun-Hong $\mathrm{CHENG}^{1, \mathrm{a}}$, Dai REN ${ }^{1, \mathrm{a}}, \mathrm{Jun}-\mathrm{Hao}$ \\ ZHANG $^{1, c}$, Han-Shan ZHANG ${ }^{1, b}$ \\ ${ }^{1}$ Zhongyuan University of Technology Henan Pro. China \\ a*email:dxw2053@126.com, bemail:466508392@qq.com ,cemail:819433644@qq.com
}

Keywords: Metal component, High rigidity, Added mass, Vibration aging, Natural frequency

\begin{abstract}
Vibratory stress relief(VSR) is carried out by using mechanical eccentric vibration aging machine. It is the common method to remove the residual stress of the metal component, with energy saving, environmental protection, highly efficiency, low cost and other advantages. However, due to the limitation of the speed of the vibration aging machine, it can't handle the natural frequency of a high stiffness metal member with an inherent frequency of $100 \mathrm{H}_{\mathrm{Z}}$. Based on the analysis of the natural frequency,added mass vibration aging method is put forward for the high rigidity metal component. By attaching the mass, structural dynamic parameters of the high rigidity metal members are adjusted, and the natural frequency of them is reduced to $100 \mathrm{H}_{\mathrm{z}}$. Taking a highly rigidity welding metal drum as the research object, by attaching the mass, the low order natural frequency is adjusted from $351.39 \mathrm{H}_{\mathrm{Z}}$ to $48.69 \mathrm{H}_{\mathrm{Z}}$. The blind hole method is adopted to test before and after the vibration aging residual stress condition. The results show that after vibration , the maximum principal stress peak value of the metal cylinder with high rigidity is decreased by $34.66 \%$, and its mean reduce to $69.84 \%$. Added mass vibration aging method can effectively reduce the residual stress of the metal component with high natural frequency.
\end{abstract}

\section{Introduction}

Vibratory stress relief(VSR) is carried out by using mechanical eccentric vibration aging machine. It is the common method to remove the residual stress of the metal component, with energy saving, environmental protection, high efficiency, low cost and other advantages. However, due to the limitation of the speed of the time machine, it can't handle the natural frequency of a high stiffness metal member with an inherent frequency of $100 \mathrm{H}_{\mathrm{Z}}$. High rigidity metal component is a widely used component in various mechanical equipment, in order to eliminate the residual stress, some scholars have put forward series vibration method, combined vibration time method, cantilever resonance method, dividing frequency vibration method, frequency spectrum and time, etc[1]. It is suitable for the treatment of small slender beam castings by the method of combination of series and vibration. Cantilever method can only be used for small stiffness, and the first order natural frequency of the plate type; Series method can be used in the form of rules, convenient connection, just the appropriate component.The fractional frequency resonance method is not very ideal for the large excitation energy and the long processing time[2].

According to vibration theory, the natural frequency of the structure is determined by the quality and rigidity of the structure. Added mass on the structure can reduce the natural frequency of the structure.

Based on natural frequency analysis, a new method for the vibration aging of high rigidity metal elements is presented. 


\section{Principle of Added Mass Vibration Aging Method}

Assuming that the free vibration differential equation of a free damped system with $\mathrm{n}$. $M \ddot{x}+K x=0$ ( $K$ for stiffness matrix, $M$ for mass matrix) the special solution is

$$
\mathrm{Xi}=\sin (\mathrm{pt}+\varphi) \quad \mathrm{i}=1,2,3, \ldots \mathrm{n}
$$

That is to set up the system of coordinates for synchronous harmonic vibration. On the type can be expressed as $X=A \sin (p t+\phi)$

Type A=(A1 A2 ...An) $\mathrm{T}$

The type (1-2) into $\mathrm{M} \ddot{\mathrm{x}}+k_{x}=0$, and the elimination of $\sin (\mathrm{pt}+\varphi)$ obtained

$$
(\mathrm{K}-\mathrm{p} 2 \mathrm{M}) \mathrm{A}(\mathrm{i})=0
$$

Based on the orthogonality of the main formation:

$$
p_{i}{ }^{2}=\frac{\left(A^{(i)}\right)^{T} K A^{(i)}}{\left(A^{(i)}\right)^{T} M A^{(i)}}=\frac{K_{i}}{M_{i}} \quad \mathrm{i}=1,2,3, \ldots \mathrm{n}
$$

By the type (3) and the type (4)

$$
\begin{array}{ll}
(\mathrm{K}-\mathrm{p} 2 \mathrm{M}) \mathrm{A}(\mathrm{i})=0 & \mathrm{i}=1,2,3, \ldots \mathrm{n} \\
p_{i}{ }^{2}=\frac{\left(A^{(i)}\right)^{T} K A^{(i)}}{\left(A^{(i)}\right)^{T} M A^{(i)}}=\frac{K_{i}}{M_{i}} & \mathrm{i}=1,2,3, \ldots \mathrm{n} \\
f_{i}=2 \pi p_{i}=2 \pi \sqrt{\frac{K_{i}}{M_{i}}} & \mathrm{i}=1,2,3, \ldots . \mathrm{n}
\end{array}
$$

From the formula (6), it can be seen that when the elements of the $K$ increase, it will increase, and when the elements in $M$ increase, it will decrease. The natural frequency of the system will increase with the increase of the coefficient of rigidity, and decrease with the increase of the quality. The following pair of formula (5) will be analyzed for mathematical calculations and changing trend.

In the $M$ matrix of the system, the elements of the matrix are unchanged, and the influence of the change of the $K$ matrix elements on the natural frequency of the system is given. For convenience, now the main mode to use regular mode, namely

$$
K A_{N}^{(i)}=p_{i}{ }^{2} M A A_{N}{ }^{(i)}
$$

A change of the $\mathrm{j}$ elastic components in the system, will be the type of derivative, getting $\frac{\delta K}{\delta k_{j}} A_{N}{ }^{(i)}+K \frac{\partial A_{N}{ }^{(i)}}{\partial k_{j}}=2 p_{i} \frac{\delta p_{i}}{\delta p_{j}} M A_{N}{ }^{(i)}+p_{i}{ }^{2} \frac{\partial M}{\partial k_{j}} A_{N}^{(i)}+p_{i}{ }^{2} M \frac{\partial A_{N}{ }^{(i)}}{\partial k_{j}}$, Because the $M$ does not contain 
elements of the stiffness, so $\frac{\partial M}{\partial k_{j}}=0$ And multiply the top end of the previous formula $\left(A_{N}{ }^{i}\right)^{T}$. getting

$$
\begin{aligned}
& \frac{\partial K}{\partial k_{j}} A_{N}{ }^{(i)}\left(A_{N}{ }^{i}\right)^{T}+\left(A_{N}{ }^{i}\right)^{T} \mathrm{k} \frac{\partial A_{N}{ }^{(i)}}{\partial k_{j}}=2 p \frac{\partial p_{i}}{\partial k_{j}} \\
& \left(A_{N}{ }^{i}\right)^{T} M A_{N}{ }^{(i)}+p_{i}{ }^{2}\left(A_{N}{ }^{i}\right)^{T} \frac{\partial M}{\partial k_{j}} A_{N}{ }^{(i)}+p_{i}{ }^{2} M\left(A_{N}{ }^{i}\right)^{T} \frac{\partial A_{N}{ }^{(i)}}{\partial k_{j}}
\end{aligned}
$$

In the type

$$
M\left(A_{N}{ }^{i}\right)^{T} A_{N}{ }^{(i)}=1
$$

Because of

$\mathrm{K} A_{N}{ }^{(i)}=p_{i}{ }^{2} \mathrm{MA} A_{N}{ }^{(i)}$, and this type of transposition, getting $\mathrm{K}\left(A_{N}{ }^{(i)}\right) \mathrm{T}={ }^{p_{i}}{ }^{2} \mathrm{MA}\left(A_{N}{ }^{(i)}\right) \mathrm{T}$, so

$$
\mathrm{K}\left({ }^{A_{N}{ }^{(i)}}\right) \mathrm{T} \frac{\partial A_{N}^{(i)}}{\partial k_{j}}=p_{i}{ }^{2} M A\left(A_{N}{ }^{(i)}\right) \mathrm{T} \frac{\partial A_{N}{ }^{(i)}}{\partial k_{j}}
$$

(10) and (11) substitution (9):

$$
\frac{\partial p_{i}}{\partial k_{j}}=-\frac{1}{2 p_{i}} \frac{\partial K}{\partial k_{j}} A_{N}^{(i)}\left(A_{N}^{i}\right)^{T} \quad \mathrm{i}=1,2,3, \ldots, \mathrm{n}
$$

The formula shows that the change of the natural frequency of the system is proportional to the change of the element.

Empathy, the elements in the system stiffness matrix $K$ remain constant, while the mass matrix $M$ is changed, that is, the quality of the $M$ is changed, at the same step, noticing $\frac{\partial K}{\partial m_{j}}=0$,

$M\left(A_{N}{ }^{i}\right)^{T} A_{N}{ }^{(i)}=1$, and simultaneous elimination $K\left(A_{N}{ }^{(i)}\right) T \frac{\partial A_{N}{ }^{(i)}}{\partial m_{j}}$ and $p_{i}{ }^{2} \mathrm{M} \frac{\partial A_{N}{ }^{(i)}}{\partial m_{j}}$ :finally getting : $\frac{\partial p_{i}}{\partial m_{j}}=\frac{1}{2 p_{i}} \frac{\partial M}{\partial m_{j}} A_{N}{ }^{(i)}\left(A_{N}{ }^{i}\right)^{T} \quad \mathrm{i}=1,2,3, \ldots, \mathrm{n}$

Upper type indicates: Mass becomes large, the natural frequency of each order decreases.

Therefore, an appropriate quality is attached to a high rigidity metal member, adjusting its structure dynamics parameters can make its low order natural frequency reduced to $100 \mathrm{H}_{\mathrm{Z}}$ below, in the vibration frequency range of the mechanical eccentric vibration exciter[3].

\section{Experimental Method of the Added Mass Vibration}

\section{Experimental Method}

As shown in Figure 1, the high stiffness of welded metal roller regarded as the research object, drum diameter of $700 \mathrm{~mm}$, length $1030 \mathrm{~mm}$. Through the modal analysis, the natural frequency of the cylinder is measured. And then add a mass on the roller, modal analysis of the metal drum after the additional mass, measured natural frequency. Adjusting its low order natural frequency to $100 \mathrm{H}_{\mathrm{Z}}$, Vibratory stress relief(VSR) is carried out by using mechanical eccentric vibration aging machine. The residual stress before and after the test of vibration aging condition is tested by using blind hole method[4]. 


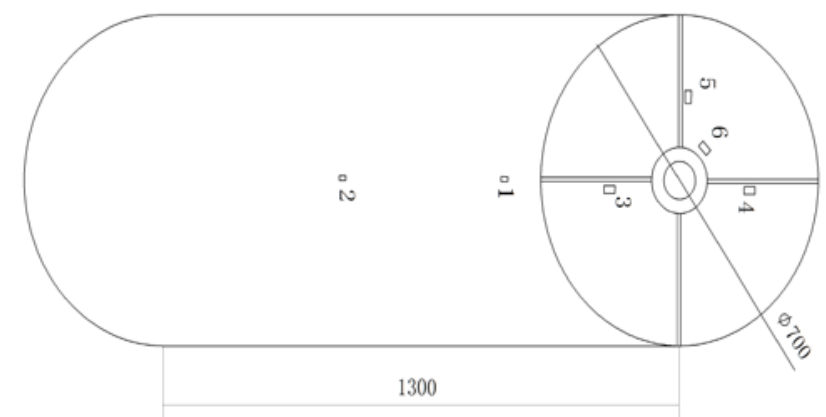

Fig.1. High rigidity system block diagram welded metal drum.

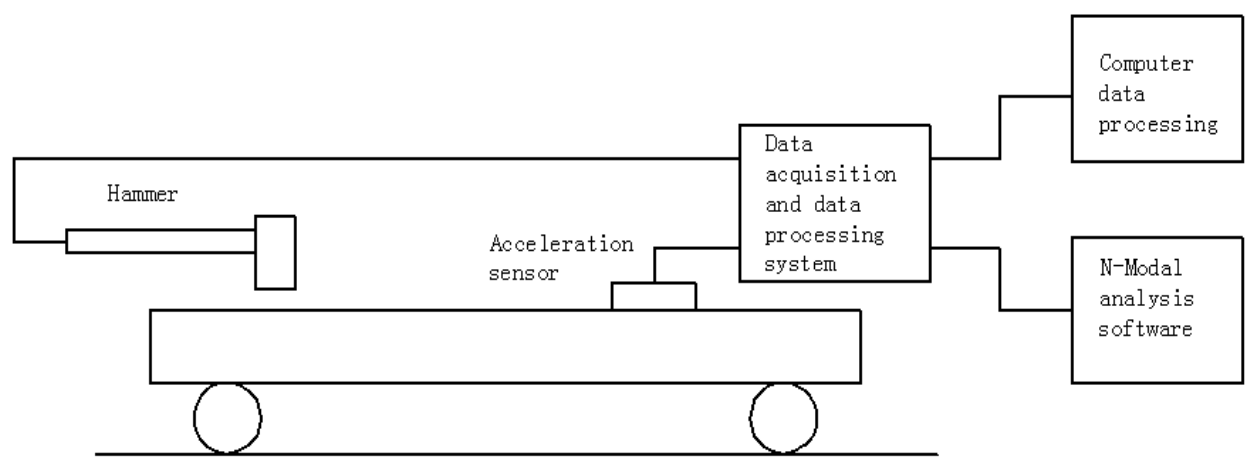

Fig.2. Modal test system.

\section{Modal Test}

Modal test system shown in Figure 2, pulse excitation method, the experimental modal analysis (EMA) of the metal drum is carried out respectively.

By the geometric modeling, data acquisition, signal processing, parameter identification, modal verification, the modal parameters of the metal drum are obtained respectively[5].

Figure 3 shows the frequen cy response curve of the added mass before and after metal drum. Table 1 is the low order natural frequencies of the metal drum for the added mass. Figure 4 is the main natural mode shapes of the low order modes of the metal drum $100 \mathrm{H}_{\mathrm{Z}}$ after the addition of mass.

Table 1. Low order natural frequency of the metal roller with the additional mass

\begin{tabular}{lll}
\hline State & Mode & Natural frequency $\left(\mathrm{H}_{\mathrm{Z}}\right)$ \\
\hline \multirow{3}{*}{$\begin{array}{l}\text { Before } \\
\text { Additional mass }\end{array}$} & The first order & 351.39 \\
\cline { 2 - 3 } & The second order & 742.84 \\
\cline { 2 - 3 } & The third order & 759.20 \\
\hline \multirow{3}{*}{$\begin{array}{l}\text { After } \\
\text { Additional mass }\end{array}$} & The first order & 48.69 \\
\cline { 2 - 3 } & The second order & 75.72 \\
\cline { 2 - 3 } & The third order & 93.69 \\
\hline
\end{tabular}



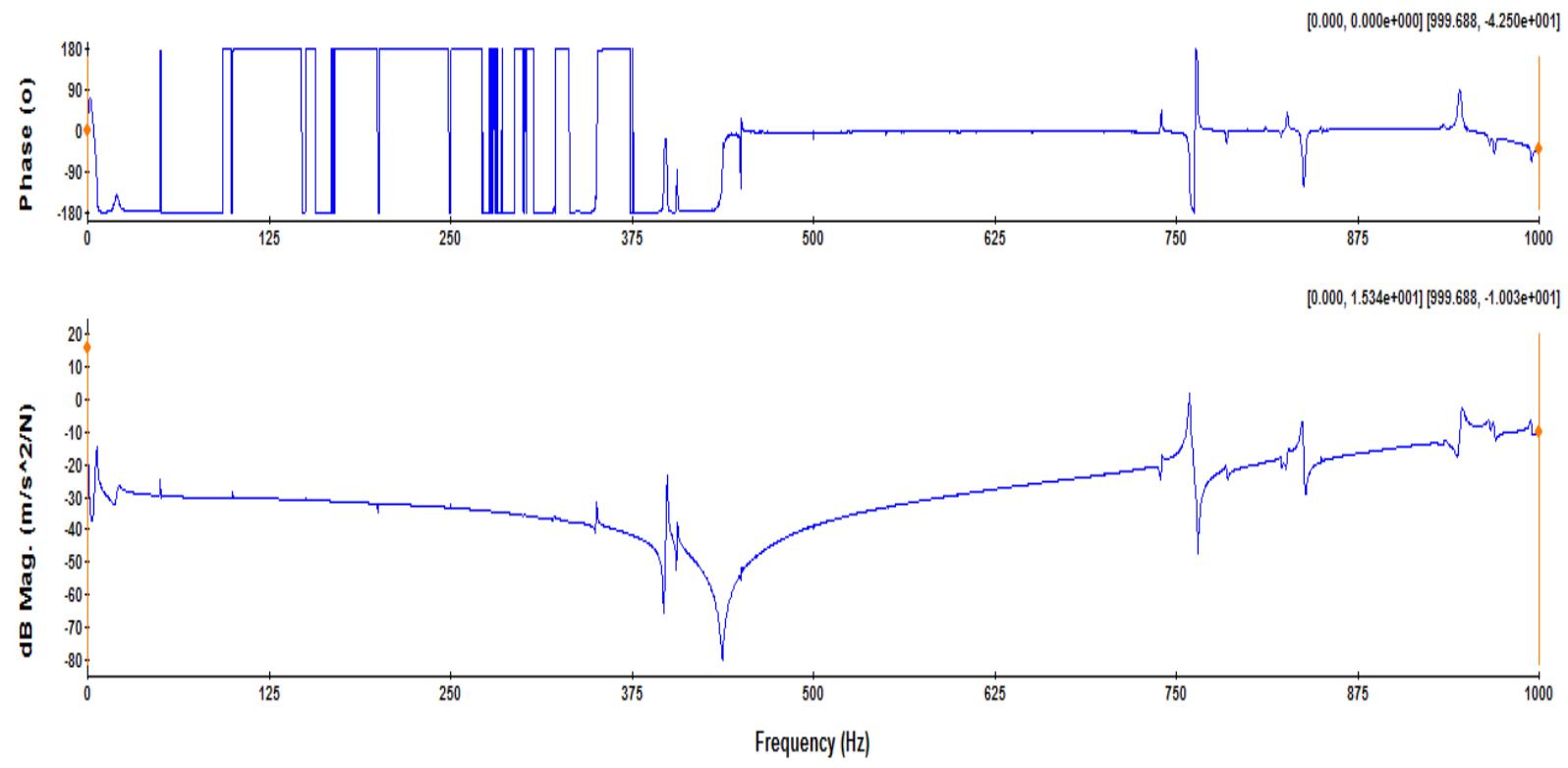

(a)

Frequency Response Function

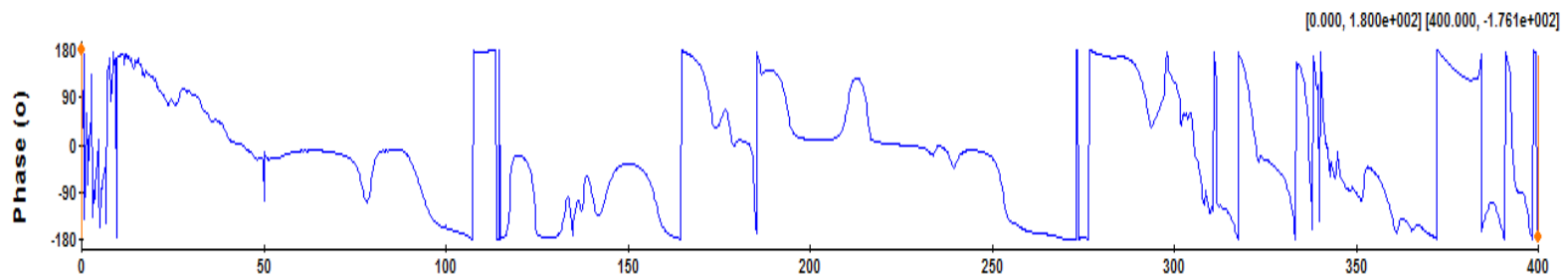

0

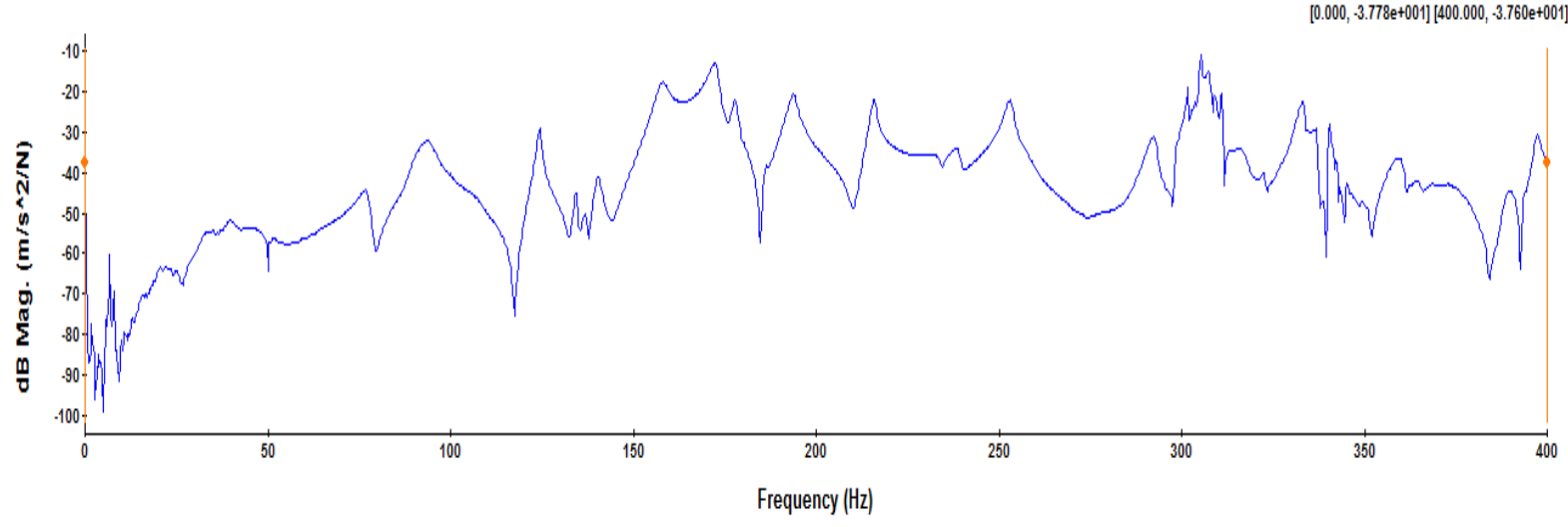

(b)

Fig.3. The frequency response function of metal drum before and after Added quality.

From the results of the modal test, the natural frequency of the metal drum is obviously decreased. The first order natural frequency of the metal cylinder is $351.39 \mathrm{H}_{\mathrm{Z}}$, which exceeds the $100 \mathrm{H}_{\mathrm{Z}}$ frequency limit of the mechanical eccentric vibration time limit for the vibration of the time machine. After adding mass, the first order natural frequency of the metal roller is reduced to $48.69 \mathrm{H}_{\mathrm{Z}}$. In Figure 4,the metal drum after additional quality whose three orders of the low order modes below the $100 \mathrm{H}_{\mathrm{Z}}$, which their mainly natural mode shapes are waist drum type and tympanic membrane vibration type vibration.Among them, in Figure 4 (a), the intrinsic frequency is $48.69 \mathrm{H}_{\mathrm{Z}}$, the modes of metal drum arer waist drum and waist drum combined modes, in Figure 4 (b), the natural frequency 
of the $75.72 \mathrm{H}_{\mathrm{Z}}$ is a drum type, in Figure 4 (c), the natural frequency of $93.69 \mathrm{H}_{\mathrm{Z}}$ is the type of the membrane.

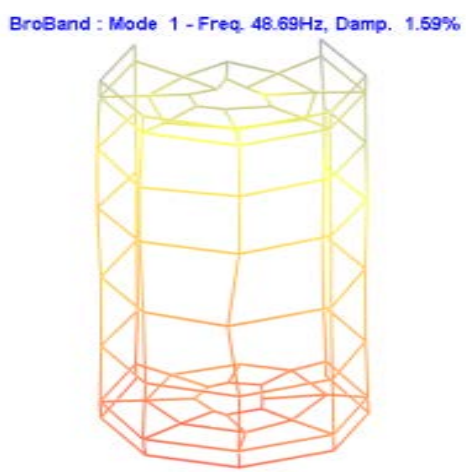

(a)

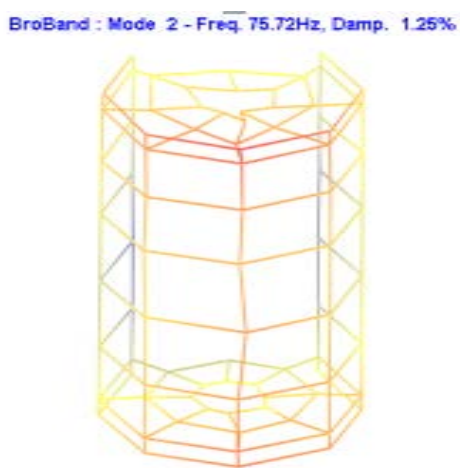

(b)

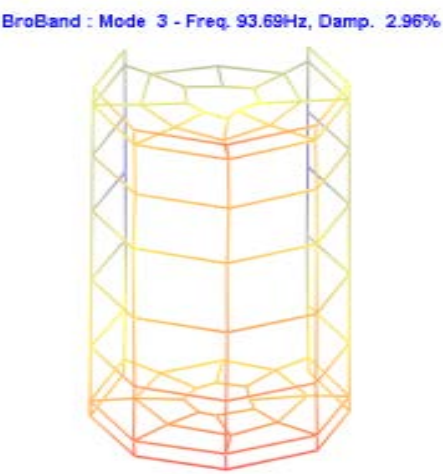

(c)

Figure 4. Low-order vibration mode of the metal drum

\section{Residual Stress Test}

In order to test the validity of the method of the added mass vibration, the vibration of the cylinder is treated by the time of the cylinder vibration, select 6 measuring points on the cylinder (as shown in Figure 1), the initial measurement of residual metal roller blind hole method is used for stress. The results are shown in Figure 5and Figure 6, the abscissa is shown in the test period, the ordinate is the residual stress value (MPa).

\section{Vibration Treatment}

Known by vibration theory, when the excitation frequency is in the low order natural frequency of the component, a larger vibration response can be produced [6]. At this moment, the vibration displacement of the structure can be excited by the small exciting force. Therefore, respectively using $48.69 \mathrm{H}_{\mathrm{Z}}$ drum of a metal drum with an additional mass and combined vibration of the drum and $75.72 \mathrm{H}_{\mathrm{Z}}$ is a two natural vibration mode of the waist, vibration treatment of metal drum. Among them, $48.69 \mathrm{H}_{\mathrm{Z}}$ vibration for 10 minutes, $75.72 \mathrm{H}_{\mathrm{Z}}$ vibration for 8 minutes, vibration acceleration is controlled in about $30 \mathrm{~m} / \mathrm{s}^{2}$.

\section{Experimental results}

For the vibration aging treatment of metal drum, the blind hole method is used as shown in Figure 5 points to measure residual stress. The results are shown in Figure 5and Figure 6.Therefor, after treatment with the addition of mass vibration aging method, the maximum principal peak value of the high rigidity metal drum is reduced from $358.3 \mathrm{MPa}$ to $234.1 \mathrm{MPa}$, reducing rate is $34.66 \%$; The maximum principal stress is reduced from $178.32 \mathrm{MPa}$ to $53.78 \mathrm{MPa}$, the reduction rate is $69.84 \%$.It is indicated that the residual stress of the metal member can be reduced effectively by the addition mass vibration aging method. 


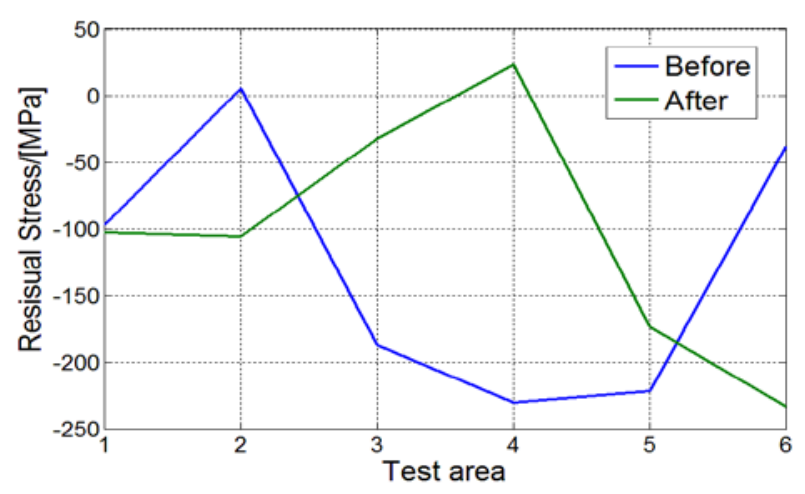

Figure $5 . \sigma_{1}$ Residual stress distribution

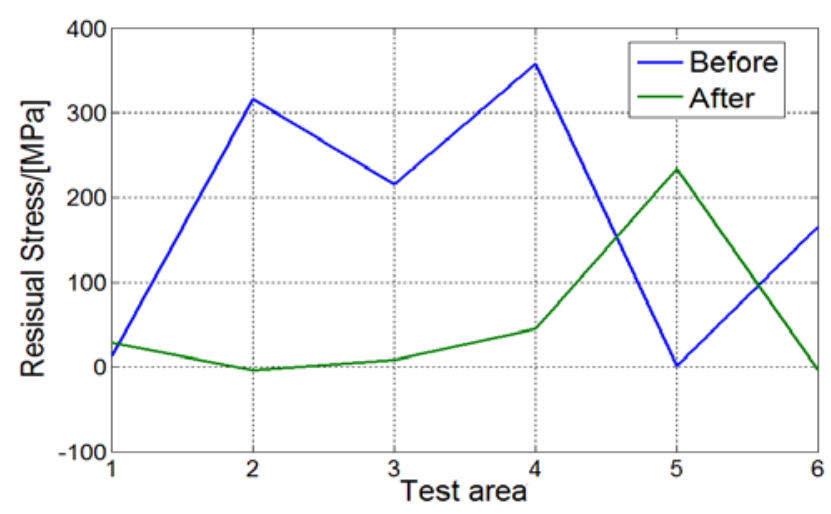

Figure $6 . \sigma_{2}$ Residual stress distribution

\section{Conclusion}

By adding appropriate mass, adjusting the structural dynamic parameters of high rigidity metal members, reducing the natural frequency of its part to $100 \mathrm{H}_{\mathrm{Z}}$, the mechanical eccentric vibration aging machine can be used for the vibration aging treatment.

Additional mass vibration aging method can effectively reduce the residual stress of the metal component with high natural frequency. The method is effective for the elimination of the residual stress in the high rigidity metal component.

\section{Reference}

[1] Qifen Jia, Xijun Liu, Wende Zhang, Engineering vibration and testing technology Tianjin University press, 2002 (3): 69-70.

[2] Xuewu Dong, Jinhao Zhan, Casting combined vibration aging method. Journal of Zhengzhou Institute of textile.1999.3.10 (1): 1-4.

[3] Xuewu Dong, Kai Zhang, Study on the effect of vibration frequency on the welding residual stress. Journal of zhongyuan univesitf of technology , 2009,17 (3): 27 -29.

[4]Munsi ASMY,Waddell A.J,Walker C.A. Vibratory weld conditioning- the effect of rigid body motion vibration during welding. Strain, 1999, 35 (4) : 139 143.

[5] XueWu Dong, Jian Hui Han, Dai Ren, Kai Mu, Zhi Min Fu, Ya Fei Zhai,Study on Vibratory Stress Relief of Cylindrical Welded Component with Energy-Saving and Environment.Applied Mechanics and Materials.May 2012.1168-1172.

[6]Xuewu Dong, Xi Zhang, Yanting Wang, Yanyan Yang, Bing Li, Dai Ren, Study on Optimization Design of VSR Parameter for Large Welded Components. Applied Mechanics and Materials.2015.136-141. 